\title{
Physical-Mechanical Properties and Durability Enhancement of Glued Laminated Lumber Made from Inner Part of Gewang (Corypha utan Lam.) Trunk: The Effect of Lamina Densification and Lumber Smoking
}

\author{
Dodi Nandika,* I Wayan Darmawan, Lina Karlinasari, Yusuf Sudo Hadi, \\ Imam Busyra Abdillah, and Julia Yonipi Putri
}

The inner part of gewang (Corypha utan Lam.) trunk has significantly lower physical-mechanical properties as well as biodeterioration resistance, compared to outer parts. This study investigated a method for improving the physical-mechanical properties and biodeterioration resistance of glued laminated lumber made from the inner part of gewang trunk (GLIT). The effects of pretreating the lamina with densification and exposing the GLIT to smoking process were investigated. The seven layers of GLIT samples were bonded with isocyanate adhesive at a glue spread of 280 $\mathrm{g} / \mathrm{m}^{2}$, then smoked for 15 days. Solid lumber pieces made from the inner part as well as the outer part of GLIT were also prepared for comparative purposes. Physical and mechanical properties of the lumber samples were tested according to Japanese agricultural standards. Meanwhile, drywood termite and wood decaying fungi resistances of the lumber samples were determined according to Indonesian standard. Results showed that overall physical-mechanical properties as well as dry-wood termite and decay resistances of densified-smoked GLIT were enhanced significantly. Pretreating of lamina and post-production smoking can be considered as a potential method to improve physical-mechanical properties and biodeterioration resistance of the GLIT.

Keywords: Gewang; Glue laminated; Hot press; Lamina densification; Mechanical properties; Smoking treatment

Contact information: Department of Forest Products, Faculty of Forestry and Environment, IPB University (Bogor Agricultural University), Bogor 16680, West Java, Indonesia;

*Corresponding authors: nandikadodi@gmail.com; dodina@apps.ipb.ac.id

\section{INTRODUCTION}

Currently, Indonesia's log production is reported to reach around 60 million $\mathrm{m}^{3} /$ year, $85 \%$ of which comes from plantation forests (Ministry of Environment and Forestry 2020). These plantations are dominated by fast-growing tree species that are cut at 5 to 8 years to provide small-diameter logs (Hadi et al. 2016). The timber from these trees contains large amounts of sap wood that has low physical-mechanical properties and is very susceptible against various wood-destroying organisms (Hadi et al. 2010a,b). On the other hand, it has been known that the demand for high-quality timber had increased significantly year by year. This requires multiple approaches, including exploration of "new timber" resources, particularly from endemic species (Nandika et al. 2020). One of the endemic tree species that grows in Nusa Tenggara Province, Indonesia is gewang (Corypha utan Lamk.) (Flach and Rumawas 1996; Irawanto 2013). 
People in East Nusa Tenggara Province usually cut the gewang tree at 30 years old, producing around 3 tons of biomass with an average density of $0.50 \mathrm{~g} / \mathrm{cm}^{3}$. This lignocellulosic material provides a source of building materials. Besides, the texture of gewang wood is very attractive and has distinctive architectural value. Therefore, people in that region traditionally use the gewang wood for housing construction, particularly for flooring as well as door or window framing. However, based on the authors' recent study, the density of the inner part of the gewang trunk (GLIT) is very low (average $0.36 \pm 0.08$ $\mathrm{g} / \mathrm{cm}^{3}$ ). In contrast, the wood from the outer part of the trunk has medium to high density (average $0.69 \pm 0.09 \mathrm{~g} / \mathrm{cm}^{3}$ ). Nandika et al. (2020) reported that the inner part of gewang trunk has less vascular bundles compared to the outer part. As such, it is understandable that modulus of elasticity and modulus of rupture of wood originating from the inner part of the trunk were significantly lower compared to the outer parts (Prasetiyo et al. 2008). This has been a major constraint for the optimal utilization of the gewang trunk as a building material. Only a few parts of the trunk can be utilized as building material, while the rest of the parts from the inner part of the trunk tend to become waste. Moreover, Nandika (2018) and Nandika et al. (2020) reported that the inner part of gewang trunk is also very susceptible to biodeterioration. This is very concerning, since it was reported that wood biodeterioration caused by termite attack in the country had broad impact and contributed to an economic loss of almost USD 1 billion in 2015 (Nandika et al. 2015).

One of the ways to utilize the inner part of gewang trunk more effectively is by transforming it into engineered wooden products such as glued laminated lumbers. Glued laminated lumber (glulam) is constructed from some particular pieces of wood, either in a straight or curved form, with the grain parallel along their longitudinal axes (Moody et al. 1999). Glulam is an alternative product for structural material that uses wood from plantation forests (Massijaya 2014) or from small diameter logs with inferior properties such as low physical and mechanical properties (Massijaya et al. 2011). Several studies to improve physical and mechanical properties of Indonesia's low quality wood species have been previously conducted, for instance Lestari et al. (2018) studied glued laminated lumber, Hendrik et al. (2016) studied laminated composite panel, and Hadi et al. (2013, 2019) studied methyl methacrylate impregnated wood. Considering that the inner part of gewang trunk has low physical and mechanical properties (Nandika et al. 2020), the authors considered densifying the laminas prior to the composing process to become glued laminated lumber. By doing so, the density as well as the modulus of elasticity (MOE) and modulus of rupture (MOR) of the laminas hopefully will be improved and therefore contribute to enhance the physical and mechanical properties of produced lumbers. Meanwhile, smoking is an alternative for improving glulam durability. Hadi et al. (2010a,b, 2012) reported that smoking treatment could improve the resistance of wood and wood products to termite attack, and its resistance classification increased by one class according to Indonesian National Standard SNI 7207-2014 (2014). A recent study revealed that decay and termite resistances of gewang wood could be improved using smoke treatment (Hadi et al. 2020a,b; Nandika et al. 2020).

Hence, this study aimed to evaluate the physical and mechanical properties as well as biodeterioration resistance of smoked glued laminated lumber made from densified inner part of gewang trunk, compared to those made from undensified lamina and also to the solid lumber of gewang trunk. 


\section{EXPERIMENTAL}

\section{Materials}

Gewang (Corypha utan) logs with a length of $1.60 \mathrm{~m}$ and a diameter of 38 to $42 \mathrm{~cm}$ from the middle part of the trunk were obtained from Kupang, East Nusa Tenggara

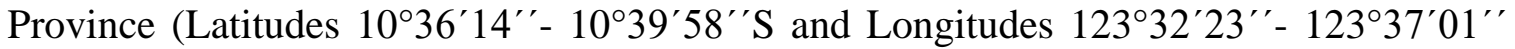
E). Two mature trees of gewang which were grown were cut as the log source.

\section{Methods}

Preparation of gewang laminas

The laminas were produced from the inner most part, which is two-thirds of the log part (also called the inner part) in the transversal direction. The demarcation point between outer part and inner part of the gewang log was determined following a study from Nandika et al. (2020). The gewang logs were cut to produce flat-sawn lumber using a bandsaw. After sizing and cutting, 140 uniformed and defect-free laminas with a particular size of $5 \mathrm{~cm} \times 1.2 \mathrm{~cm} \times 160 \mathrm{~cm}$ (in width, thickness, and length, respectively) were selected for glued laminated lumbers production. Solid lumbers $(5 \mathrm{~cm}$ x $5.4 \mathrm{~cm}$ x $160 \mathrm{~cm})$ made from the inner part as well as the outer part of the logs were also prepared for comparative purposes. The laminas and the solid lumbers were stored in a closed shed up to their moisture content stabilization level of $12.5 \pm 1.5 \%$.

\section{Lamina densification}

The laminas originated from the inner part of the trunk were divided into two groups: one group of lamina was densified and another group was undensified. The density of lamina before the densification process was $0.37 \pm 0.09 \mathrm{~g} / \mathrm{cm}^{3}$. Hot compressing with $150{ }^{\circ} \mathrm{C}$ and pressure of $2.94 \mathrm{MPa}$ using Weili 2000MH38 Series was applied to the lamina for $60 \mathrm{~min}$ (Prabuningrum et al. 2020). The laminas were originally $5 \mathrm{~cm} \times 1.2 \mathrm{~cm} \times 160$ $\mathrm{cm}$ (in width, thickness, and length, respectively). They were densified to be $5 \mathrm{~cm} \times 0.77$ $\mathrm{cm} \times 160 \mathrm{~cm}$.

\section{Laminated lumber manufacture (composing of lamina)}

Laminated lumber, measuring $5 \mathrm{~cm}$ x $5.40 \mathrm{~cm}$ x $160 \mathrm{~cm}$ in width, thickness, and length, respectively, was produced from seven layers of lamina measuring $5 \mathrm{~cm} \times 0.77 \mathrm{~cm}$ $\mathrm{x} 160 \mathrm{~cm}$. The composition (position) of lamina in each laminated lumber was arranged according to each lamina's MOE, in which the face and back layers of the laminated lumber (layer 1 and 7) was composed by the highest MOE (first grade lamina). The layer 2 and 6 were composed of the second grade of lamina. In addition, the layer 3 and 5 were composed by third grade. Lamina with the lowest MOE was located as the core layer. Through these processes, the authors produced two types of glued laminated lumber made from GLIT as follows:

- GLIT composed of lamina without densification (undensified)

- GLIT composed of lamina with densification (densified)

Isocyanate (base: hardener $=100: 15$ ), produced by PT Polychemie Asia Pasific Indonesia (Jakarta Indonesia), was used to bond the laminas with a glue spread of $280 \mathrm{~g} / \mathrm{m}^{2}$ per single glue line (Komariah et al. 2015). After the adhesive were spread on the surface of the laminas, composed laminas were cold pressed with $0.98 \mathrm{MPa}$ for $3 \mathrm{~h}$ to produce GLIT (Komariah et al. 2015). After these processes, conditioning at room temperature 
was applied to the produced glue laminated lumbers for 1 week. Five solid lumber pieces from the inner part (SLIT) with size of $5 \mathrm{~cm} \times 5.4 \mathrm{~cm} \times 160 \mathrm{~cm}$ in which width, thickness, and length, respectively, as well as from the outer part (SLOT) of gewang trunk were also prepared for comparison. The cross section of the GLIT and solid lumber are presented in Fig. 1.
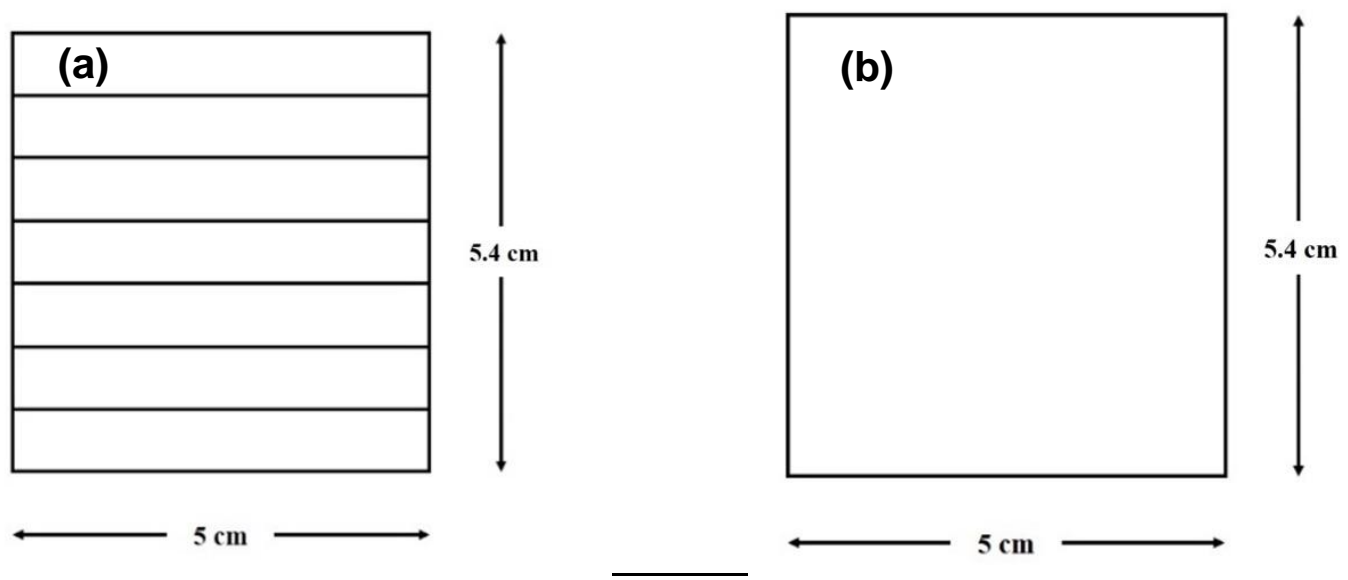

Fig. 1. Cross section of the laminated lumber (a) and solid lumber (b)

\section{Smoking procedure}

The produced lumbers were divided into two groups: one group was smoked and another group was unsmoked. The smoking process was conducted according to Nandika et al. (2020). Smoking treatment for 15 days was applied to the GLIT in a smoking chamber. In this process, kesambi (Schleichera oleosa) wood, which had a density of 0.69 $\pm 0.10 \mathrm{~g} / \mathrm{cm}^{3}$, was pyrolyzed to produce smoke. The smoking chamber consisted of two tanks; the first tank functioned as a pyrolysis room which produced hot smoke. The smoke then flowed to the second tank to reduce the smoke temperature down to 18 to $36{ }^{\circ} \mathrm{C}$ and filter the tar. Following the smoking process, all lumber samples were conditioned at room temperature $\left(20.1\right.$ to $\left.31.1{ }^{\circ} \mathrm{C}\right)$ and relative humidity of 62.5 to $95.6 \%$. Considering the densification of lamina prior to glue laminated lumber composing as well as the smoking process of produced lumbers, in total the authors produced eight types of lumber, consisting of four types of glue laminated lumbers and four types of solid lumbers. From each type of lumber, the authors prepared five samples as replications for the tests. The cutting pattern of produced lumbers for preparing test samples is presented in Fig. 2.

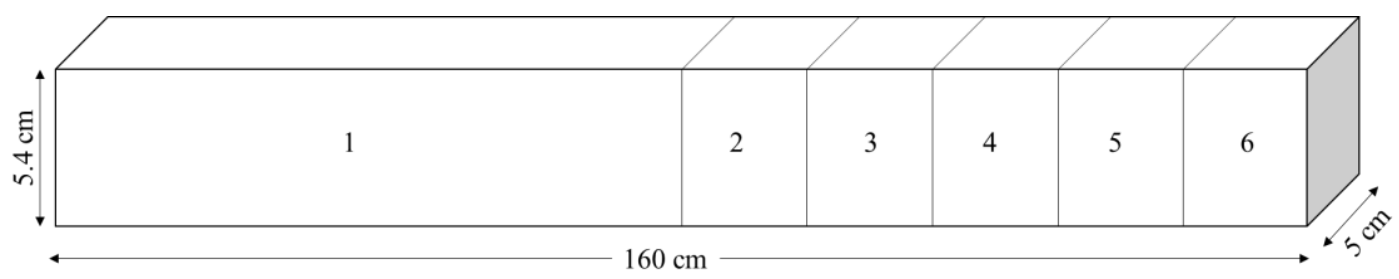

Fig. 2. Cutting pattern of produced lumbers for preparing test samples. $1=$ the test sample for MOE/MOR $(5 \mathrm{~cm} \times 5.4 \mathrm{~cm} \times 76 \mathrm{~cm}) ; 2=$ the test sample for moisture content $(\mathrm{MC})$ and density $(5$ $\mathrm{cm} \times 5.4 \mathrm{~cm} \times 5 \mathrm{~cm}) ; 3=$ the test sample for shear strength $(5 \mathrm{~cm} \times 5.4 \mathrm{~cm} \times 5 \mathrm{~cm}) ; 4=$ the test sample for dry-wood termite resistance $(2.5 \mathrm{~cm} \times 2.7 \mathrm{~cm} \times 5 \mathrm{~cm}) ; 5=$ the test sample for decay fungus resistance $(2.5 \mathrm{~cm} \times 2.7 \mathrm{~cm} \times 5 \mathrm{~cm})$, and $6=$ the test sample for delamination $(5 \mathrm{~cm} \times 5.4$ $\mathrm{cm} \times 5 \mathrm{~cm}$ ) 


\section{Physical and mechanical properties test}

The physical properties, MC and density, as well as mechanical properties, MOE, MOR, and shear strength, of the lumber samples were tested according to Japanese Agricultural Standard JAS 234-2003 (2003) regarding glued laminated timber. Modulus of elasticity and MOR tests used one-point loading with a span length of $76 \mathrm{~cm}$ and a loading speed of $6.6 \mathrm{~mm} / \mathrm{min}$, using Universal Testing Machine Instron Series 3369. The MOE, MOR, and shear strength were calculated (Eqs. 1 through 3),

$$
\begin{aligned}
& \text { MOE }(\mathrm{GPa})=\frac{\Delta P \times L^{3}}{4 \times \Delta y \times b \times h^{3}} \\
& \operatorname{MOR}(\mathrm{MPa})=\frac{3 \times P \times L}{2 \times b \times h^{2}} \\
& \text { Shear strength }=\frac{\text { Rupture load }}{\text { Area of bonding layer }}
\end{aligned}
$$

where $\Delta P$ is the difference between the upper and lower loading limits in the proportional limit region $\left(\mathrm{kg}_{\mathrm{f}}\right) ; \Delta y$ is the deflection with respect to $\Delta P(\mathrm{~cm}) ; L$ is the span $(\mathrm{cm}) ;$ and $b$ and $h$ are the width and thickness, respectively, of the test specimen $(\mathrm{cm})$.

\section{Delamination test}

The cold-water delamination test was carried out by soaking lumber samples in water at room temperature for $6 \mathrm{~h}$, then putting the samples into the oven at a temperature of $40 \pm 3{ }^{\circ} \mathrm{C}$ for $18 \mathrm{~h}$. In addition, hot water delamination was done by boiling the lumber samples in hot water $\left(100^{\circ} \mathrm{C}\right)$ for $4 \mathrm{~h}$, then soaking it in water at room temperature for 1 hour before placing it in an oven at $70 \pm 3{ }^{\circ} \mathrm{C}$ for $18 \mathrm{~h}$. Both delamination tests were carried out according to JAS 234-2003 (2003) using a water bath. The delamination ratio was calculated using the following formula 4 :

$$
\text { Delamination ratio }(\%)=\frac{\text { sum of delaminated lengths of two cross sections }}{\text { sum of gluing lengths of two cross sections }} \times 100 \%
$$

\section{Resistance test against dry-wood termite}

Sample measuring of $2.5 \mathrm{~cm} \times 2.7 \mathrm{~cm} \times 5 \mathrm{~cm}$, in width, thickness, and length, respectively, from each type of lumbers were prepared according to Indonesian standard SNI 7207-2014 (2014). Each sample was placed in the center of a glass tube $(1.8 \mathrm{~cm}$ in diameter, $3 \mathrm{~cm}$ high), then 50 of the dry-wood termite Cryptotermes cynocephalus Light were introduced into each glass tube. The glass tubes were then placed in a dark room for 12 weeks. Each type of lumber sample had five replications. At the end of the experiment, weight loss and termite mortality percentages were determined. The lumber sample resistance was classified according to the Indonesian standard SNI 7207-2014 (2014), which described in Table 1. The weight loss and termite mortality percentage were determined with Eqs. 5 and 6,

$$
\begin{aligned}
& \text { WL }(\%)=\frac{\left(W_{b}-W_{d}\right)}{W_{b}} \times 100 \% \\
& \text { Mortality }(\%)=\frac{\left(T_{\mathrm{b}}-T_{\mathrm{d}}\right)}{T_{\mathrm{b}}} \times 100 \%
\end{aligned}
$$

where is $\mathrm{WL}$ is weight loss percentage, $W_{\mathrm{b}}$ is the weight of the sample before the test at oven-dried condition, $W_{\mathrm{d}}$ is weight of the sample after the test at oven-dried condition, $T_{\mathrm{b}}$ is the live termite number before the test, and $T_{\mathrm{d}}$ is the live termite number after the test. 
Table 1. Classification of Wood Resistance Against Dry-wood Termites

\begin{tabular}{|c|c|c|}
\hline Class & Sample Condition & Weight Loss (\%) \\
\hline I & Very resistant & $<2.0$ \\
\hline II & Resistant & $2.0-4.4$ \\
\hline III & Moderate & $4.4-8.2$ \\
\hline IV & Poor & $8.2-28.1$ \\
\hline V & Very poor & $>28.1$ \\
\hline
\end{tabular}

Resistance test against fungus decay

The inoculation of wood-decaying fungus, Schizophyllum commune, was carried out in the glass boxes using potato dextrose agar as media for 10 days (Herliyana et al. 2011).

Individual samples measuring $2.5 \mathrm{~cm} \times 2.7 \mathrm{~cm} \times 5 \mathrm{~cm}$ in width, thickness, and length, respectively, from each type of lumbers were placed on the fungus isolate in the glass box for the test according to Indonesian standard SNI 7207-2014 (2014). The test was conducted in an incubator at a temperature ranging from 22 to $28^{\circ} \mathrm{C}$ and 80 to $90 \%$ relative humidity for 10 weeks. At the end of the test, the weight loss percentage of the sample was determined. The sample resistance was classified according to the Indonesian standard SNI 7207-2014 (2014), as presented in Table 2.

Table 2. Classification of Wood Resistance Against Fungal Decay

\begin{tabular}{|c|c|c|}
\hline Class & Sample Condition & Weight Loss (\%) \\
\hline I & Very resistant & $<0.5$ \\
\hline II & Resistant & 0.5 to 4.9 \\
\hline III & Moderate & 5.0 to 9.9 \\
\hline IV & Poor & 10.0 to 30.0 \\
\hline V & Very poor & $>30.0$ \\
\hline
\end{tabular}

\section{Data Analysis}

A 2 by 2 factorial completely randomized design was used to analyze the data, where the first factor (factor A) was the pretreatment applied to the lamina (densification and undensification), and the second factor (factor B) was the treatment applied to the produced lumber (smoked and unsmoked). After variance analysis, Duncan's multiple range test was used for further analysis if the interaction factor was significantly different at $\mathrm{p} \leq 0.05$.

\section{RESULTS AND DISCUSSION}

\section{Physical Properties of GLIT \\ Moisture content}

The MC of four type of GLIT ranged from $10.60 \%$ to $13.36 \%$ (Fig. 3). The MC of all GLIT met the JAS 234-2003 (2003) standard, which requires a maximum value of $15 \%$. Kretschmann and Green (1996) stated that MC and density are basic quality indicators that influence the strength of wood; the lower the $\mathrm{MC}$, the higher the wood strength. The average MC of the GLIT was $11.75 \%$. The figure was understandable since the constituent laminas had MC values ranging from $11.92 \%$ to $13.70 \%$. Komariah et al. (2015) stated that the $\mathrm{MC}$ of laminated lumber is influenced by the MC of each constituent lamina. 
Meanwhile, the MC of solid lumbers of gewang trunk ranged from $12.85 \%$ and $15.11 \%$ respectively (Fig. 3).

Based on the variance analysis shown in Table 3, it was revealed that the MC of GLIT was influenced by densification applied to the lamina and the smoking process, but not by the interaction of the two factors. It was found that the MC of GLIT composed of densified lamina, both smoked and unsmoked, was lower than the MC of GLIT composed of undensified lamina that was then smoked. However, the MC of the GLIT was not significantly different from GLIT composed of undensified lamina that were then applied with smoking treatment. In addition, it was also found that the MC of almost all GLIT samples were lower than the MC of solid lumber samples, except GLIT composed of undensified lamina that were then smoked. It appears that, in general, smoking treatment decreased the MC of the lumber.

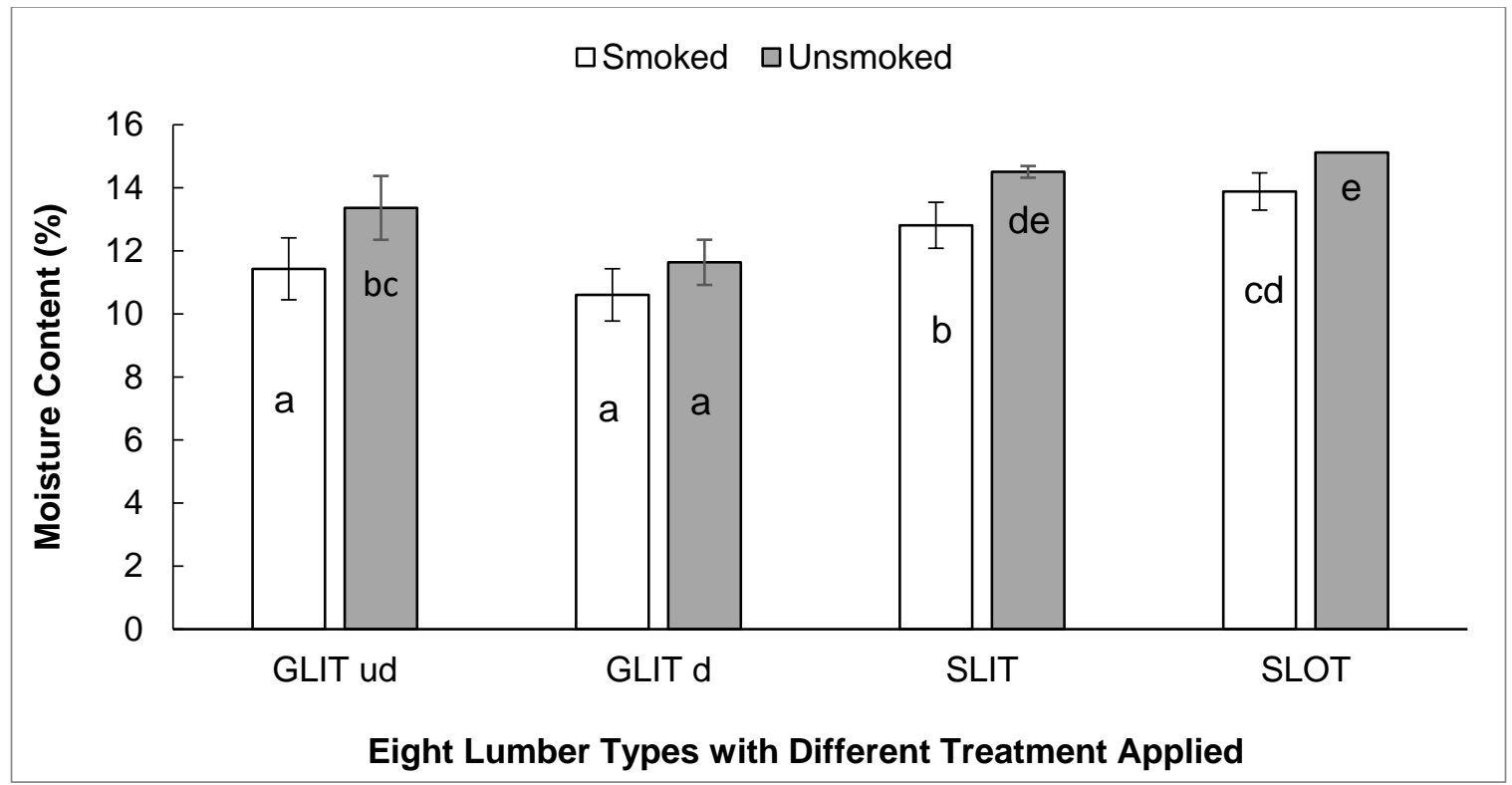

Fig. 3. MC value of the GLIT and solid lumber pieces of gewang. Different letters denote statistically different values at $p<0.05)$.

Table 3. Variance Analysis of the Physical-mechanical Properties and Biodeterioration Resistance of the Gewang Lumbers

\begin{tabular}{|l|c|c|c|}
\hline \multicolumn{1}{|c|}{ Parameter } & $\begin{array}{c}\text { Densification } \\
(\mathbf{A})\end{array}$ & $\begin{array}{c}\text { Smoking Process } \\
(\mathbf{B})\end{array}$ & $\begin{array}{c}\text { Densification \& } \\
\text { Smoking (AB) }\end{array}$ \\
\hline $\mathrm{MC}(\%)$ & ${ }^{*}$ & ${ }^{* *}$ & $\mathrm{NS}$ \\
\hline Density $\left(\mathrm{g} / \mathrm{cm}^{3}\right)$ & ${ }^{* *}$ & $\mathrm{NS}$ & $\mathrm{NS}$ \\
\hline $\mathrm{MOE}(\mathrm{GPa})$ & ${ }^{* *}$ & $\mathrm{NS}$ & $\mathrm{NS}$ \\
\hline MOR (MPa) & ${ }^{* *}$ & $\mathrm{NS}$ & $\mathrm{NS}$ \\
\hline Shear strength $(\mathrm{MPa})$ & ${ }^{* *}$ & $\mathrm{NS}$ & $\mathrm{NS}$ \\
\hline Delamination ratio $(\%)$ & ${ }^{* *}$ & ${ }^{* *}$ & $\mathrm{NS}$ \\
\hline $\begin{array}{l}\text { Resistance to termite, } \\
\text { weight loss (\%) }\end{array}$ & $\mathrm{NS}$ & ${ }^{* *}$ & $\mathrm{NS}$ \\
\hline Termite mortality $(\%)$ & $\mathrm{NS}$ & ${ }^{* *}$ & \\
\hline $\begin{array}{l}\text { Resistance to fungi, } \\
\text { weight loss (\%) }\end{array}$ & $\mathrm{NS}$ & & \\
\hline
\end{tabular}

Description: ${ }^{* \star}$ highly significant $(p<0.01)$; ${ }^{*}$ significant $(p<0.05)$; NS: not significant 


\section{Density}

The density of the GLIT produced ranged from 0.31 to $0.69 \mathrm{~g} / \mathrm{cm}^{3}$, with the highest density being obtained with the GLIT composed of densified lamina and the produced lumber was unsmoked $\left(0.69 \mathrm{~g} / \mathrm{cm}^{3}\right)$. Meanwhile, density of solid lumber ranged from 0.34 to $0.81 \mathrm{~g} / \mathrm{cm}^{3}$. The density of produced lumber is presented in Fig. 4 .

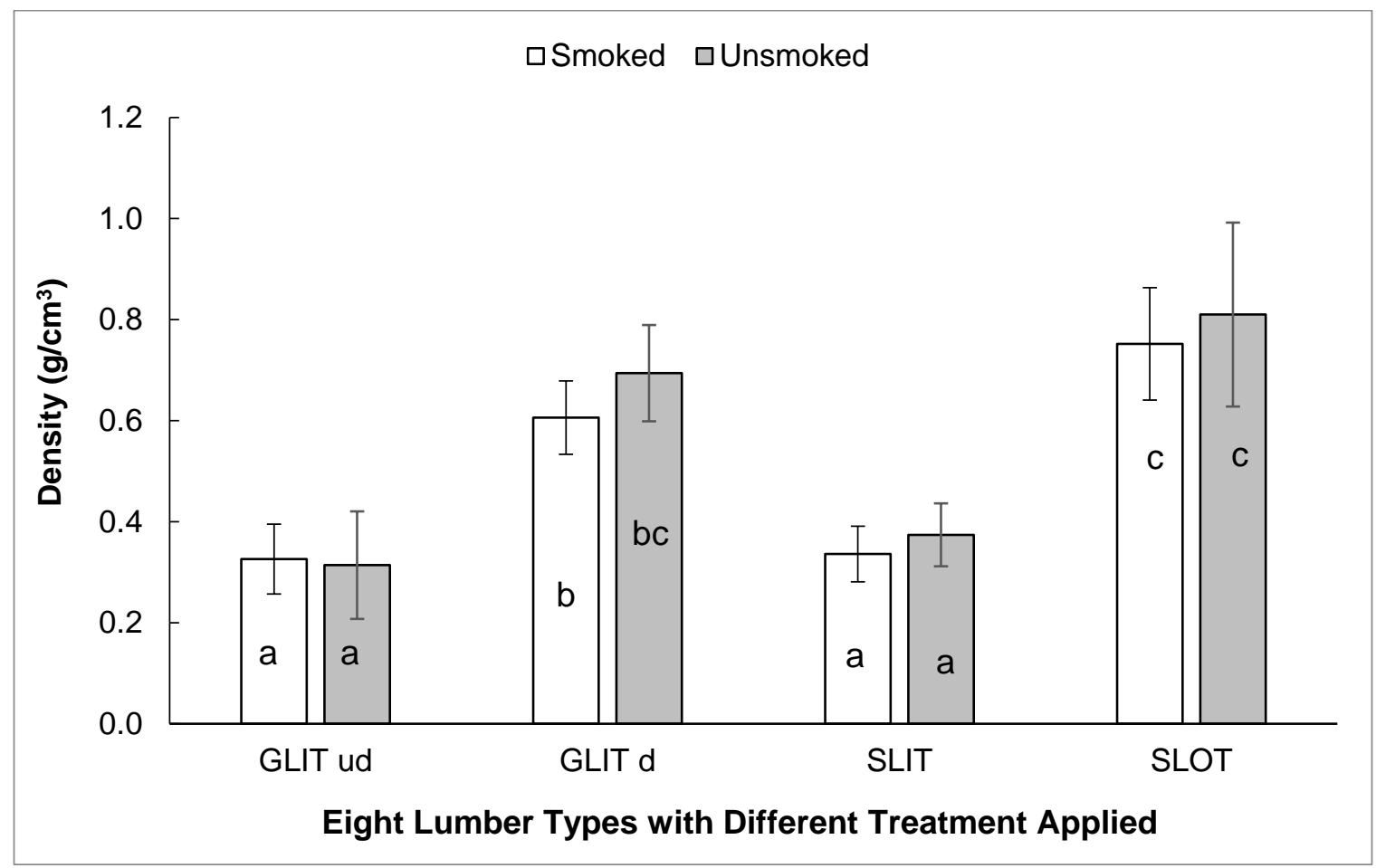

Fig. 4. Density of the GLIT and solid lumber pieces of gewang. Different letters denote statistically different values at $p<0.05$ ).

The variance analysis results in Table 3 showed that lamina densification significantly affected the density of GLIT, while the smoking treatment did not affect the density of GLIT as well as the solid lumbers. It was found that density of GLIT composed of densified lamina was higher than density of GLIT composed of undensified lamina, both smoked and unsmoked, as well as density of solid lumber made from the inner part of gewang trunk. The density values of GLIT composed of densified lamina, both smoked $\left(0.61 \mathrm{~g} / \mathrm{cm}^{3}\right)$ and unsmoked $\left(0.69 \mathrm{~g} / \mathrm{cm}^{3}\right)$, were higher than density of glue laminated panels made from sengon $\left(0.31\right.$ to $\left.0.32 \mathrm{~g} / \mathrm{cm}^{3}\right)$ and jabon wood $\left(0.44\right.$ to $\left.0.47 \mathrm{~g} / \mathrm{cm}^{3}\right)$ as studied by Hendrik et al. (2016). Sengon and jabon are widely known as two Indonesia fast growing tree species that are commonly used in the wood composite industry in the country. However, density of GLIT composed of densified lamina were still lower than density of solid lumber made from the outer part of gewang trunk, both smoked and unsmoked. Pramunendar and Supriyanto (2014) developed a density classification for Indonesia's sawn timber and proposed three class: low density (lower than $0.50 \mathrm{~g} / \mathrm{cm}^{3}$ ), medium density $\left(0.50\right.$ to $\left.0.70 \mathrm{~g} / \mathrm{cm}^{3}\right)$, and high density (higher than $\left.0.70 \mathrm{~g} / \mathrm{cm}^{3}\right)$. According to this classification, GLIT composed of densified lamina belong to medium density, while solid lumber made from the outer part of gewang trunk belong to high density. In contrast, density of solid lumber made from the inner part of gewang trunk belong to low density. 


\section{Mechanical Properties of GLIT \\ Modulus of elasticity}

The MOE of four types of GLIT ranged from 1.72 to $5.16 \mathrm{GPa}$ (Fig. 5). None of the GLIT fulfilled the JAS 234-2003 (2003) standard, which sets the MOE value minimum at $7.35 \mathrm{GPa}$. However, MOE of GLIT composed of densified lamina, both smoked (4.64 GPa) and unsmoked (5.16 GPa), was almost $250 \%$ higher compared to the MOE of GLIT composed of undensified lamina as well as solid lumber made from the inner part of gewang trunk. Meanwhile, MOE of solid lumbers made from the outer part of gewang trunk, both smoked (8.86 GPa) and unsmoked (9.18 GPa), met the JAS 234-2003 (2003) standard (Fig. 5).

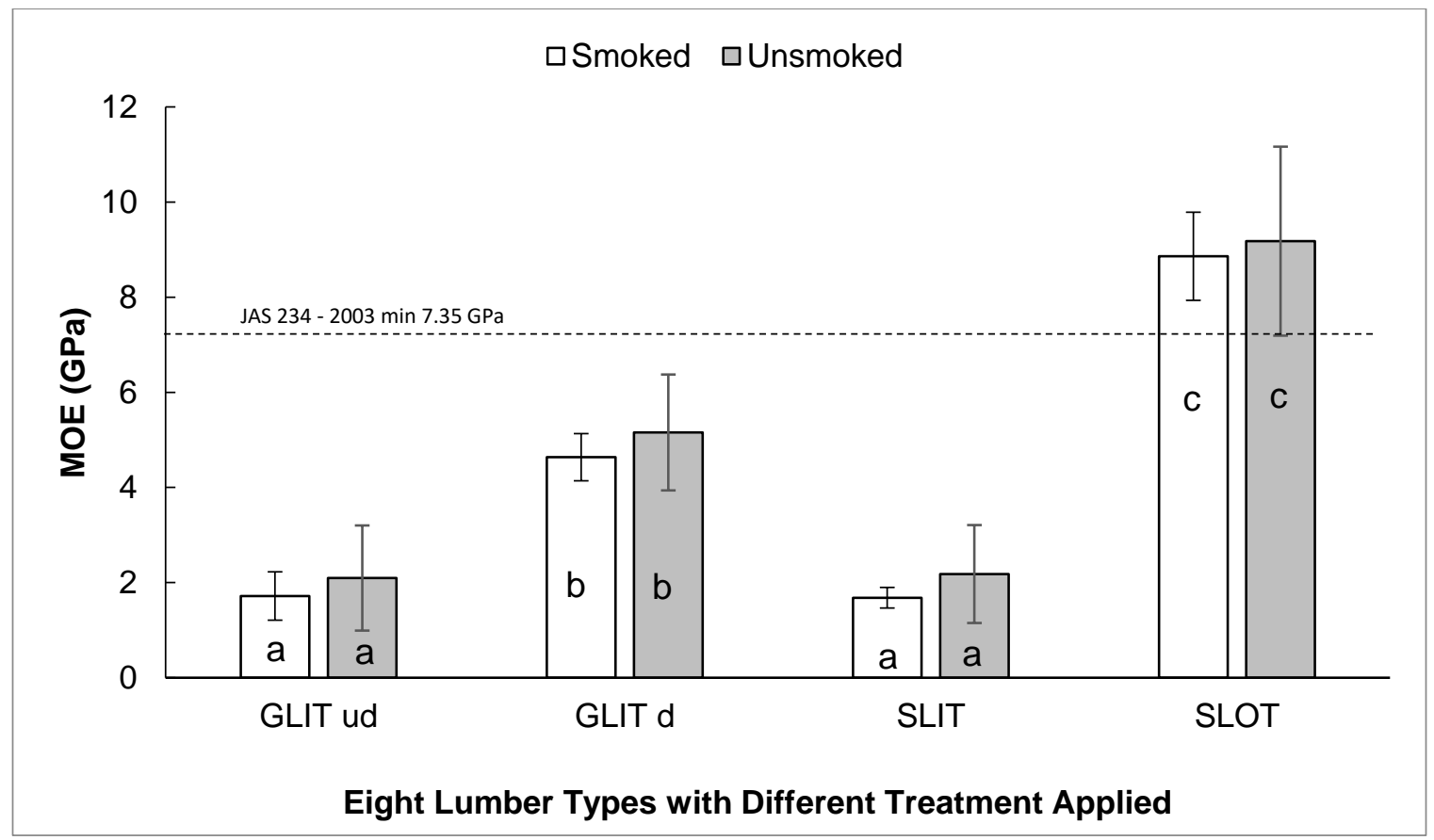

Fig. 5. MOE of the GLIT and solid lumber pieces of gewang. Different letters denote statistically different values at $p<0.05$ ).

According to variance analysis in Table 3, the densification of lamina prior to GLIT manufacturing influenced the MOE of the produced GLIT, while the smoking treatment did not affect the density of the GLIT as well as the solid lumbers. It was found that MOE of GLIT composed of densified lamina, was higher than MOE of GLIT composed of undensified lamina, both smoked and unsmoked, as well as MOE of solid lumber made from the inner part of gewang trunk. Furthermore, the MOE of GLIT composed of densified lamina, both smoked (4.64 GPa) and unsmoked (5.16 GPa), were higher than MOE of glue laminated panels made from jabon wood $(4.25 \mathrm{GPa})$ as studied by Hendrik et al. (2016). However, MOE values of GLIT composed of densified lamina were still lower than MOE of solid lumber made from the outer part of gewang trunk, both smoked $(8.86 \mathrm{GPa})$ and unsmoked $(9.18 \mathrm{GPa})$. In short, the densification process that was applied to the lamina prior to GLIT manufacturing was not able yet to produce GLIT with the same or higher MOE than the MOE shown by solid lumber made from the outer part of gewang trunk. 


\section{Modulus of rupture}

The MOR of the four types of GLIT ranged from 14.28 to $31.86 \mathrm{MPa}$ (Fig. 5). The MOR of GLIT composed of densified lamina, both smoked (31.86 MPa) and unsmoked (30.14 MPa), fulfilled the JAS 234-2003 (2003) standard, which requires a minimum value of 29.42 MPa. Meanwhile, MOR of solid lumbers ranged from 15.25 to 43.03 MPA, in which solid lumber that was made of the outer part of gewang trunk, both smoked (43.03 $\mathrm{MPa}$ ) and unsmoked (30.14 MPa), showed the highest MOR and met the JAS 234-2003 (2003) standard (Fig. 6).

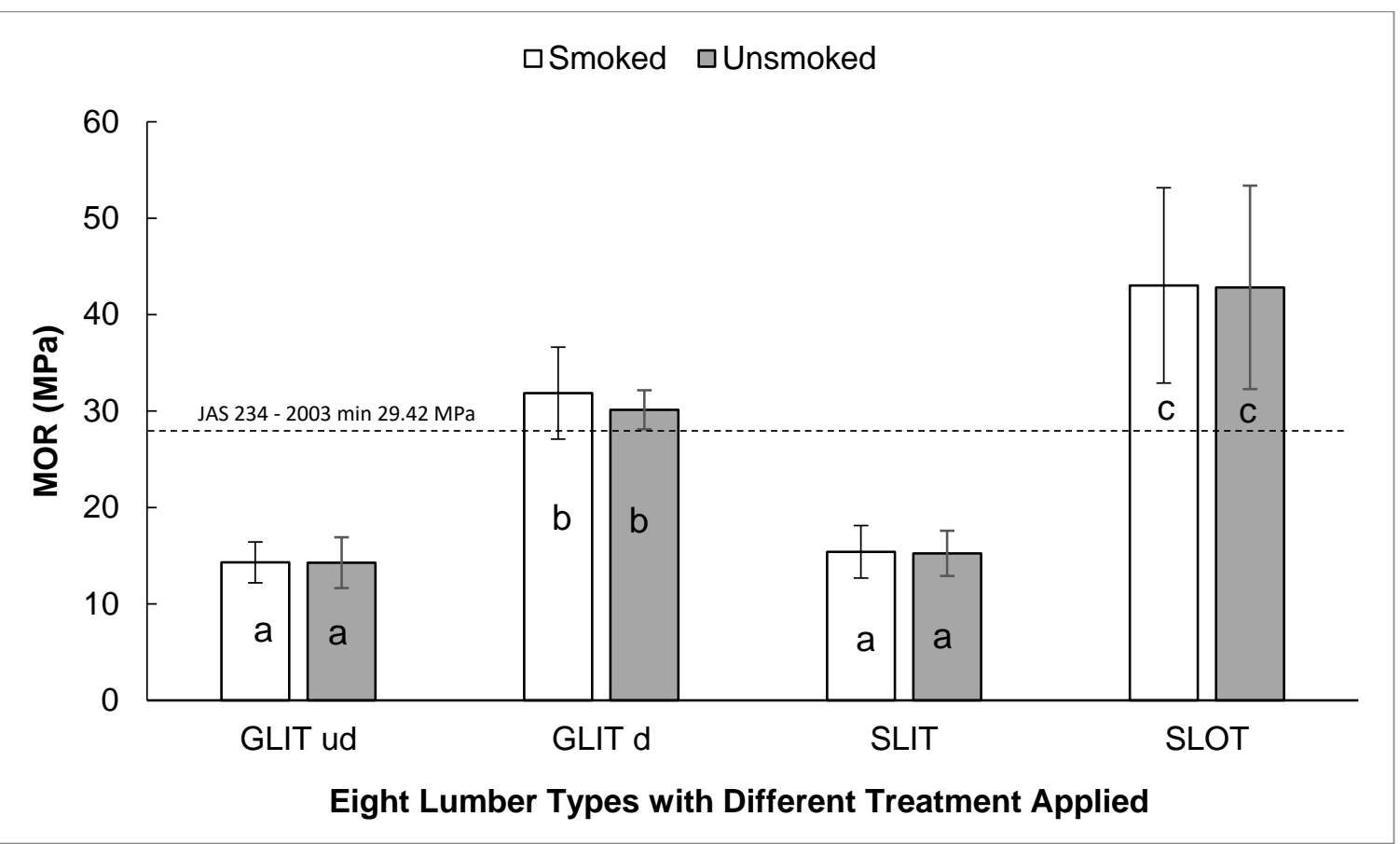

Fig. 6. MOR of the GLIT and solid lumber pieces of gewang. Different letters denote statistically different values at $p<0.05$ )

According to variance analysis in Table 3, the densification of lamina prior to GLIT manufacturing influenced the MOR of the produced GLIT, while the smoking treatment did not affect the MOR of the GLIT as well as the solid lumbers. It was found that MOR of GLIT composed of densified lamina, was higher than MOR of GLIT composed of undensified lamina, both smoked and unsmoked, as well as MOR of solid lumber made from the inner part of gewang trunk. Furthermore, the MOR of GLIT composed of densified lamina, both smoked (31.86 MPa) and unsmoked (30.14 MPa), were higher than MOR of glue laminated panels made from jabon wood $(25.55 \mathrm{MPa})$ as studied by Hendrik et al. (2016). However, MOR values of GLIT composed of densified laminas were still lower than MOR of solid lumber made from the outer part of gewang trunk, both smoked and unsmoked. In short, the densification process that was applied to the lamina prior to GLIT manufacturing was not yet able to produce GLIT with the same or higher MOR than the MOR shown by solid lumber made from the outer part of gewang trunk. Lestari et al. (2018) reported that the density of constituent lamina affected the glulam MOR: the use of a higher density lamina resulted a higher density of the glulam.

\section{Shear strength}


The shear strength in dry condition of the four types of GLIT ranged from 1.78 to 4.15 MPa (Fig. 7). All GLIT composed of densified lamina, both smoked (3.83 MPa) and unsmoked (4.15 MPa) failed to fulfil the JAS 234-2003 (2003) standard that required a minimum of $5.29 \mathrm{MPa}$. Meanwhile, the shear strength of solid lumbers ranged from 1.50 MPa to 9.08 MPA, in which solid lumber made of the outer part of gewang trunk, both smoked (9.08 MPa) and unsmoked (9.01 MPa), showed the highest shear strength and met the JAS 234-2003 (2003) standard (Fig. 6). Santoso et al. (2016) reported that the high density of glulam showed high shear strength.

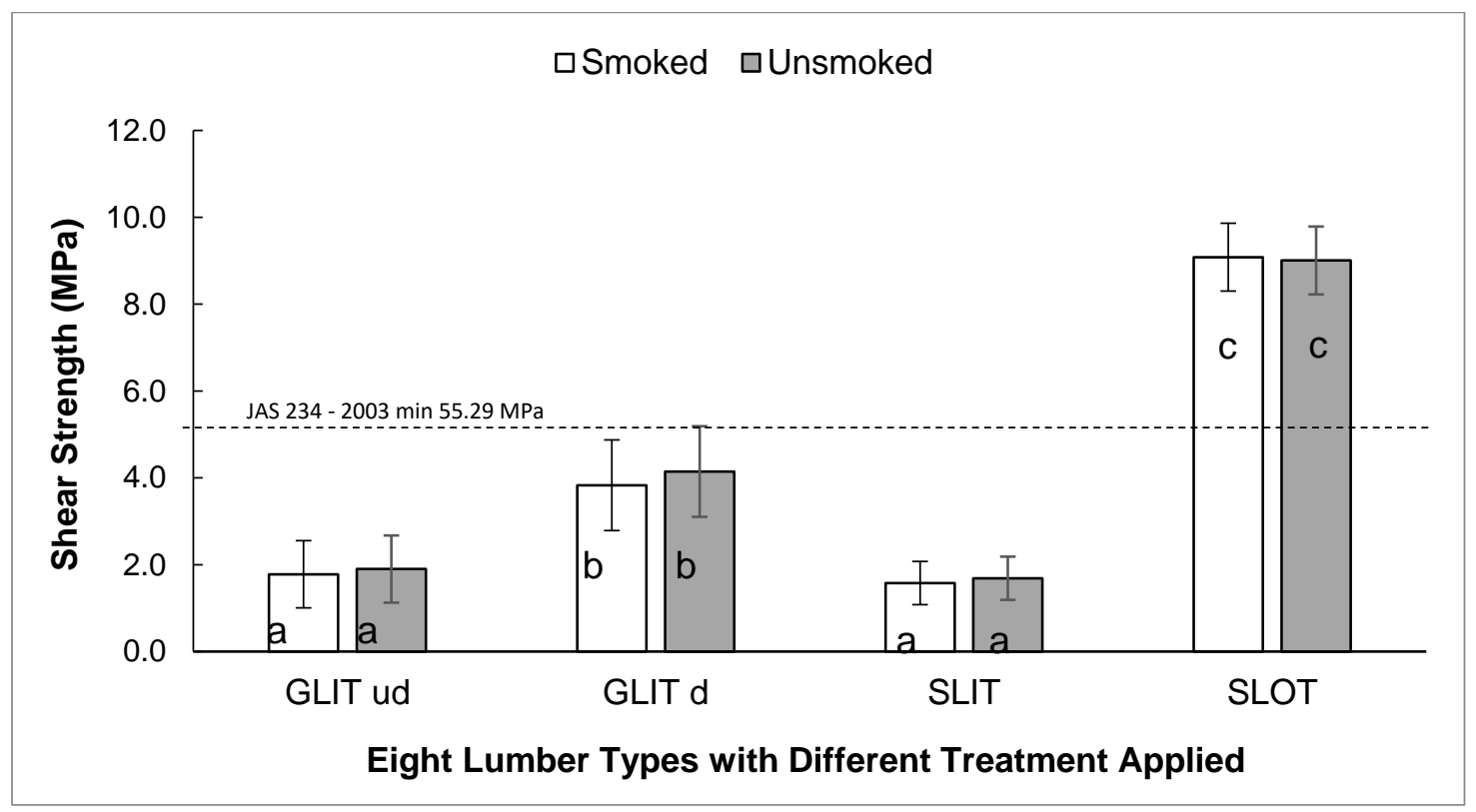

Fig. 7. Shear strength of the GLIT and solid lumber pieces of gewang. Different letters denote statistically different values at $p<0.05$ ).

According to variance analysis in Table 3, the densification of lamina prior to GLIT manufacturing influenced the shear strength of the produced GLIT, while the smoking treatment did not affect the shear strength of the GLIT as well as the solid lumbers. It was found that shear strength of GLIT composed of densified lamina was higher than the shear strength of GLIT composed of undensified lamina, both smoked and unsmoked, as well as the shear strength of solid lumber made from the inner part of gewang trunk. The shear strength of GLIT composed of densified lamina, both smoked (3.83 MPa) and unsmoked (4.15 MPa), were higher than shear strength of glue laminated panels made from jabon wood (2.47 MPa), as studied by Hendrik et al. (2016). However, shear strengths of GLIT composed of densified lamina were still lower than shear strength of solid lumber made from the outer part of gewang trunk, both smoked (9.08 MPa) and unsmoked (9.01 MPa). In short, the densification process that was applied to the lamina prior to GLIT manufacturing was not yet able to produce GLIT with the same or higher shear strength as the shear strength shown by solid lumber made from the outer part of gewang trunk.

Delamination ratio

The results of the cold-water delamination test indicate that GLIT composed of undensified lamina, both smoked and unsmoked, had no delamination (Fig. 8). The particular GLIT also showed limited delamination ratio $(9.87 \%$ for smoked and $8.49 \%$ for unsmoked) in the hot-water delamination test (Fig. 9). 


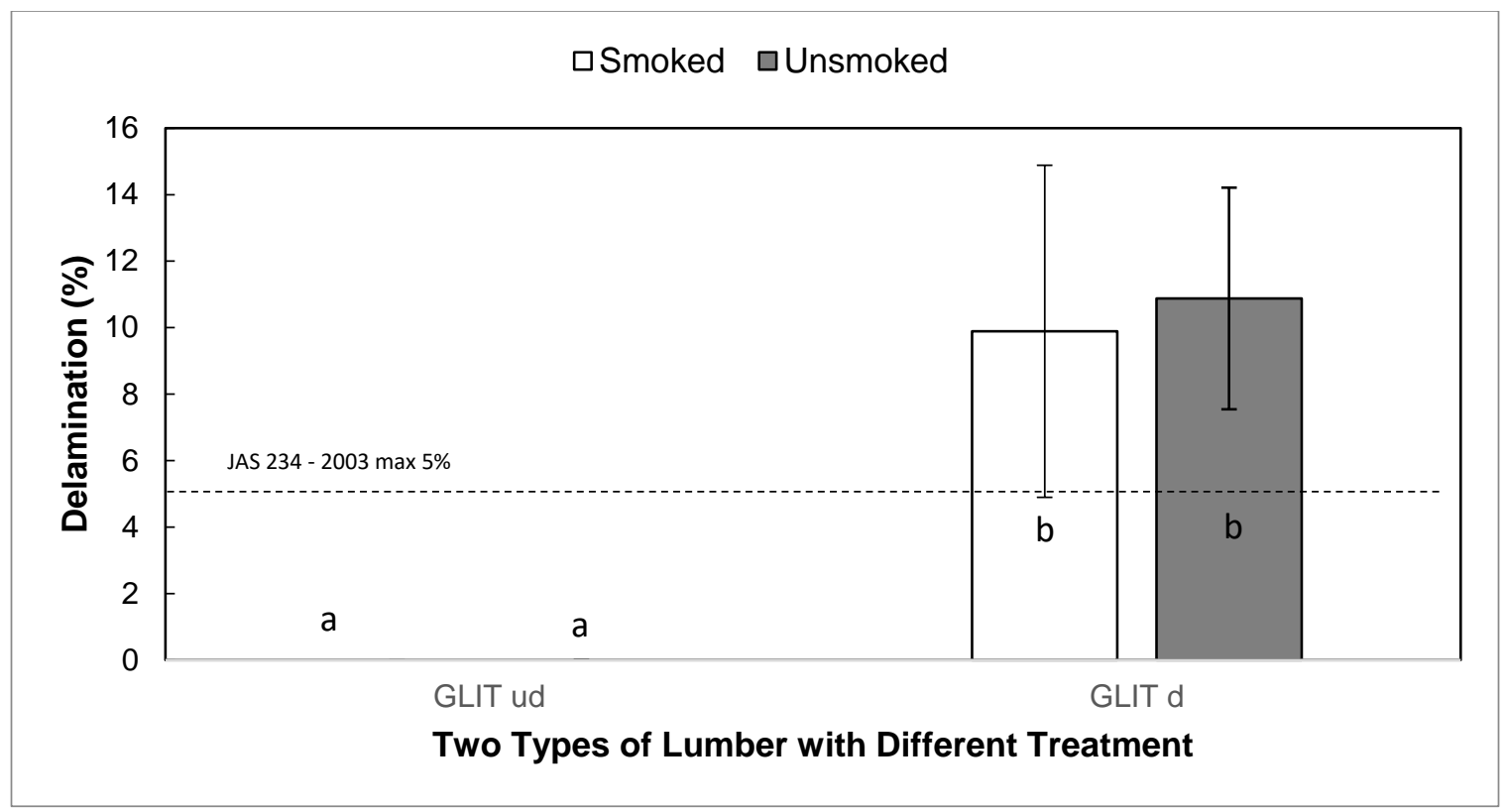

Fig. 8. Delamination in cold water test of the GLIT of gewang. Different letters denote statistically different values at $p<0.05)$.

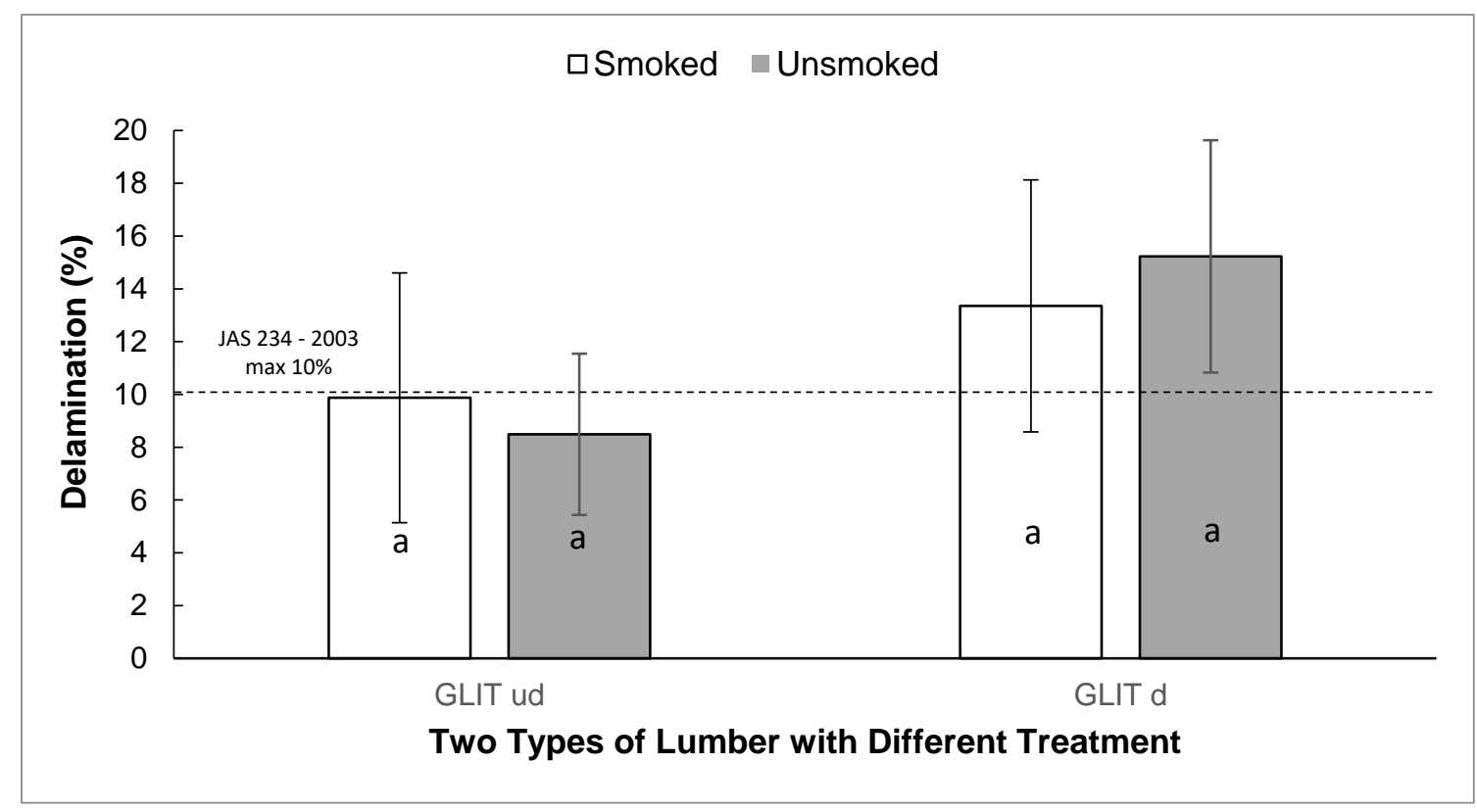

Fig. 9. Delamination in hot water test of the GLIT of gewang. Different letters denote statistically different values at $p<0.05$ ).

These phenomena are understandable, since the undensified lamina has a low density, so that the glue could penetrate more deeply into the lamina compare to densified lamina. Meanwhile, delamination on smoked and unsmoked GLIT composed of densified lamina in the cold-water delamination test were $9.89 \%$ and $10.88 \%$ respectively, and did not fulfil the JAS 234-2003 (2003) standard, with the required maximum of 5\%. In line with the findings, the results of the hot-water delamination test revealed that none of GLIT 
met the JAS 234-2003 (2003) standard, with the required maximum of 10\%. As such, GLIT composed of densified lamina can only be utilized for interior use, such as window or door framing. Subyakto et al. (2005) reported that traditionally the outer part of the gewang trunk is commonly used for flooring to replace wooden parquet, as well as for other interior housing components. By this research finding, it is expected that the smoked GLIT composed of densified lamina can be considered as an alternative building material in particular regions, and can lead to more effective utilization of the inner part of the gewang trunk.

Variance analysis in Table 3 revealed that only lamina densification treatment affected the delamination ratio, the GLIT composed of undensified lamina had better delamination resistance than GLIT composed of densified lamina.

\section{Resistance of the lumber samples to dry-wood termite}

Termite mortality on GLIT and solid lumber samples after 12 weeks of the test are displayed in Fig. 10. Smoking treatment significantly affected termite mortality. Lamina densification did not affect the termite mortality. The termite mortality on all smoked GLIT as well as on all smoked solid lumber reached $100 \%$, while on unsmoked GLIT it ranged from $34.80 \%$ to $70 \%$.

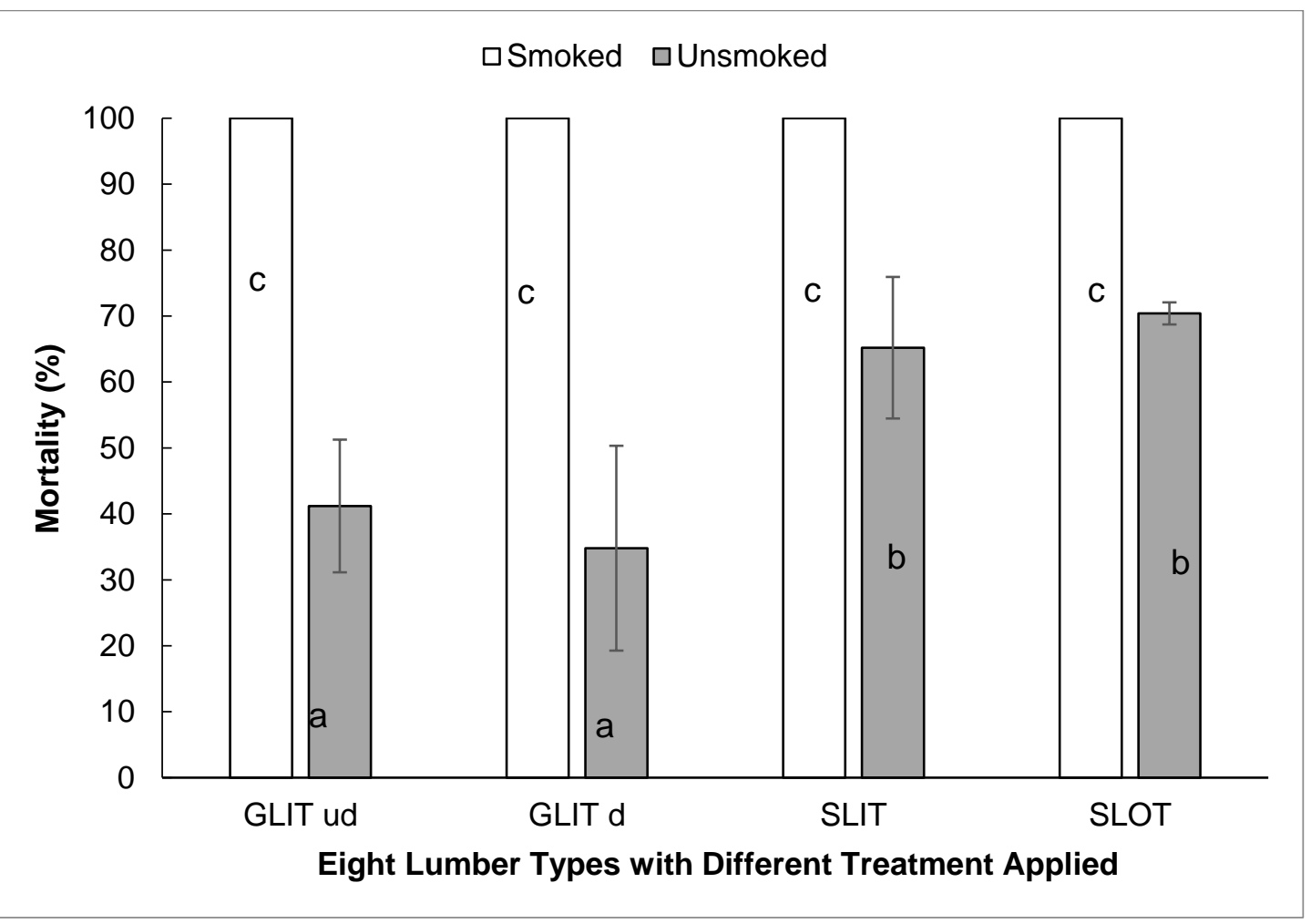

Fig. 10. Mortality of dry-wood termite C. cynocephalus on GLIT and solid lumber pieces after 12 weeks of testing. Different letters denote statistically different values at $p<0.05$ ).

The termite mortality on unsmoked GLIT, both composed of undensified lamina as well as densified lamina, were only $41.20 \%$ and $34.80 \%$ respectively. Regarding the high termite mortality on smoked lumbers, Hadi et al. $(2020 \mathrm{a}, \mathrm{b})$ reported that the smoke which contained ketone, acetic acid, phenol, benzene, and amines created a toxic environment for the termite. The weight loss percentage value of the four types of GLIT after being exposed 
to dry-wood termite $C$. cynocephalus ranged from $7.16 \%$ to $18.13 \%$. Meanwhile, the weight loss percentage value of solid lumbers ranged from $7.28 \%$ to $16.96 \%$ (Fig. 11).

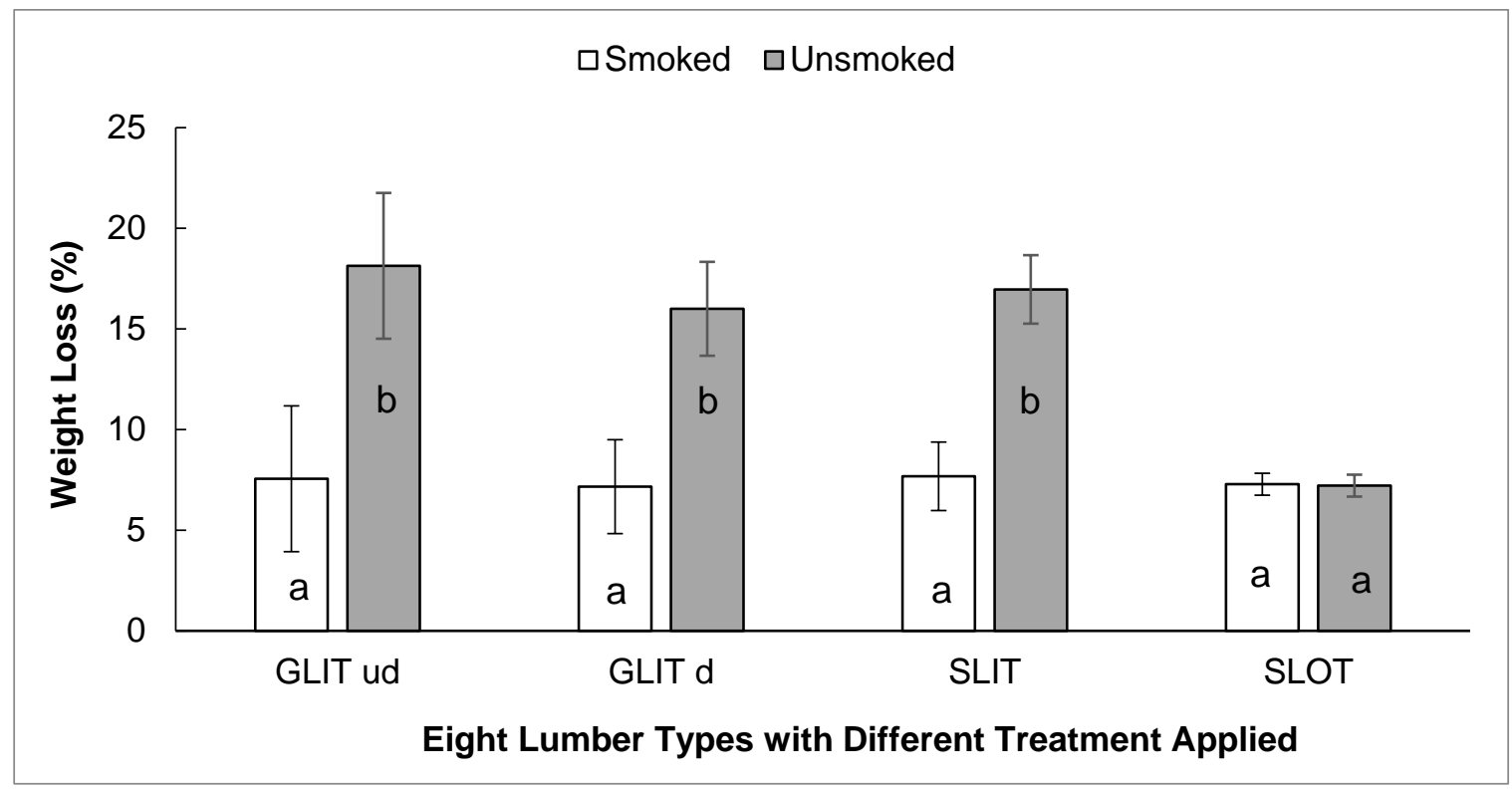

Fig. 11. Weight loss percentage of the GLIT and solid lumber pieces of gewang after exposure to dry-wood termite $C$. cynocephalus. Different letters denote statistically different values at $p<0.05$ )

Based on the variance analysis (Table 3), it was revealed that the weight loss of GLIT was influenced by smoking treatment applied to the lumbers. Meanwhile, lamina densification did not significantly affect the weight loss of GLIT. The weight loss of smoked GLIT, both composed of densified lamina as well as undensified lamina, was lower than weight loss of unsmoked GLIT. In addition, weight loss percentage of the smoked GLIT was not significantly different with the solid lumber made from the outer part of gewang trunk. It appears that smoking treatment could enhance the biodeterioration resistance of the GLIT as well as solid lumber made from the inner part of gewang trunk. Referring to the Indonesian standard SNI 7207-2014 (2014) presented in Table 1, the smoked GLIT and the solid lumber made from the outer part of gewang trunk belong to class III or that of moderate resistance to dry-wood termite, while the unsmoked GLIT belong to class IV or that of poor resistance. In other words, the smoked GLIT had one class higher than the unsmoked GLIT, and this finding was also revealed by a previous study which reported that smoke treatment improves resistance up to one class higher in samples (Hadi et al. 2010a,b, 2020a,b; Nandika et al. 2020).

\section{Resistance of lumber samples to decay fungi}

The weight loss percentage value of the four types of GLIT after 10 weeks of being exposed to decay fungi ranged from $3.70 \%$ to $12.32 \%$. Meanwhile, the weight loss percentage value of solid lumbers ranged from $2.50 \%$ to $15.28 \%$ (Fig. 12). 


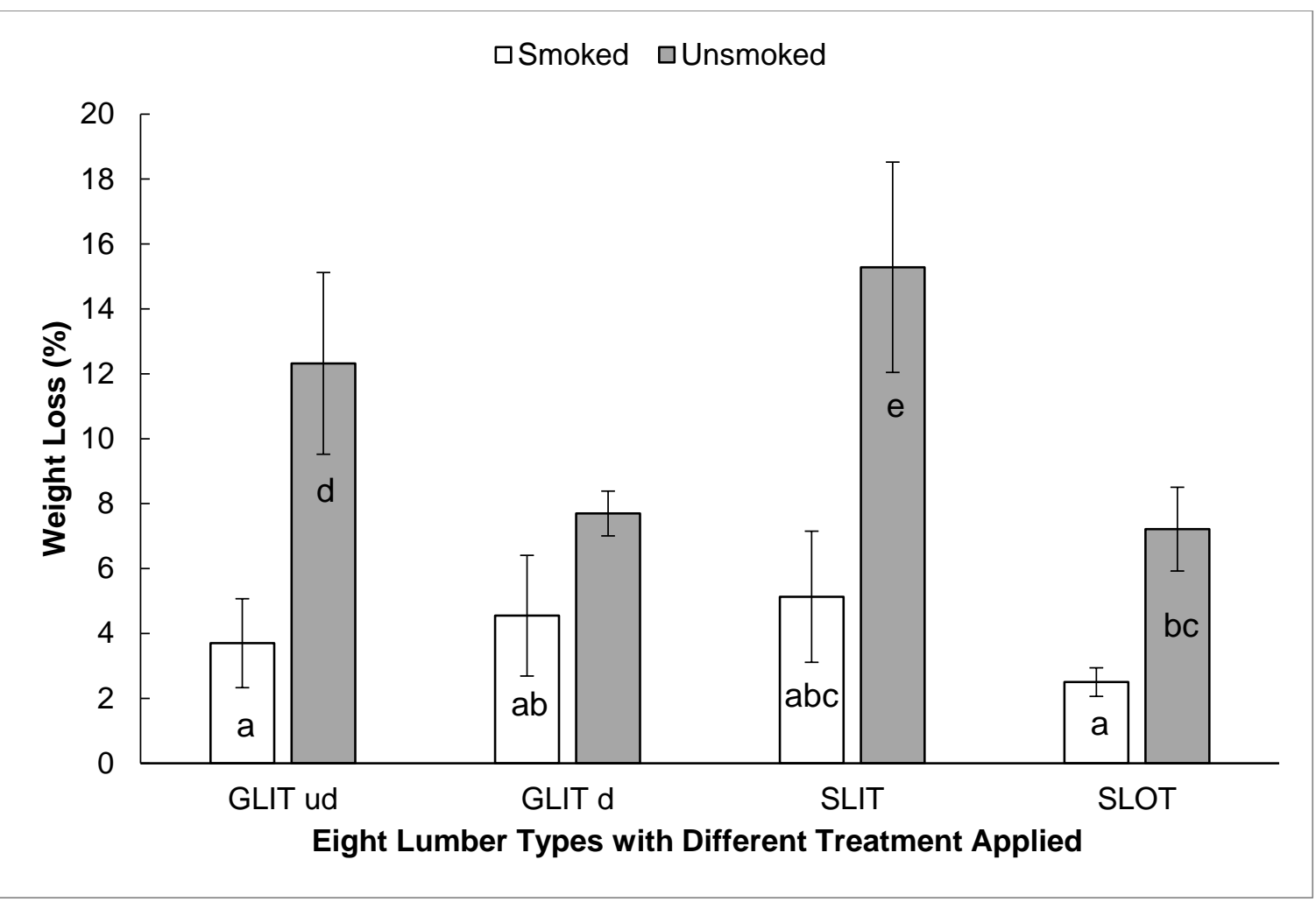

Fig. 12. Weight loss percentage of the GLIT and solid lumber pieces of gewang after 10 weeks of being exposed to decay fungus $S$. commune. Different letters denote statistically different values at $p<0.05)$.

Based on the variance analysis presented in Table 3, it was revealed that the weight loss of GLIT was influenced by smoking treatment applied to the lumbers. Meanwhile, lamina densification did not significantly affect the weight loss of GLIT. It was found that weight loss of smoked GLIT, both composed of densified lamina as well as undensified lamina, was lower than weight loss of unsmoked GLIT. In addition, the weight loss percentage of the smoked GLIT was not significantly different from the smoked solid lumber made from the inner part as well as the outer part of gewang trunk. It appears that smoking treatment could enhance the biodeterioration resistance of the GLIT as well as solid lumber made from gewang trunk. Referring to the Indonesian standard SNI 72072014 (2014) presented in Table 2, the smoked GLIT as well as the solid lumber belonged to class II or that of resistance against decay of fungus $S$. commune, while the unsmoked GLIT belonged to class III or that of moderate resistance and class IV or that of poor resistance. In other wood, the smoked GLIT had been enhanced by 1 to 2 classes compared with the unsmoked GLIT.

\section{CONCLUSIONS}

1. Overall physical and mechanical properties of glulam composed of densified lamina made from the inner part of gewang trunk were enhanced and significantly higher than glulam composed of undensified lamina as well as the solid lumber made from the same material. 
2. Smoking treatment was very effective in enhancing the resistance of glulam composed of the inner part of gewang trunk to dry-wood termite and fungal decay attacks.

3. Since densified glulam composed of the inner part of gewang trunk did not meet the JAS 234-2003 (2003) standard for the delamination test, it is recommended that the lumber should be considered for use in interior building components only.

\section{ACKNOWLEDGMENTS}

Acknowledgment and award are conveyed to the Directorate of Research and Community Service, the Directorate General of Higher Education, the Ministry of

Education, Culture, Research and Technology of the Republic of Indonesia for the funding support of this research (FY 2020-2021).

\section{REFERENCES CITED}

Flach, M., and Rumawas, F. (1996). “Corypha utan L.," Plant Resources of South East Asia (PROSEA) Foundation, Bogor, Indonesia, pp. 169-170.

Hadi, Y. S., Nurhayati, T., Jasni, Yamamoto, H., and Kamiya, N. (2010a). "Smoked wood resistance against termite," Journal of Tropical Forest Science 22(2), 127-132.

Hadi, Y. S., Nurhayati, T., Jasni, J., Yamamoto, H., and Kamiya, N. (2010b). "Smoked wood as an alternative for wood protection against termites," Forest Products Journal 60(6), 496-500. DOI: 10.13073/0015-7473-60.6.496

Hadi, Y. S., Nurhayati, T., Jasni, J., Yamamoto, H., and Kamiya, N. (2012). "Smoked wood resistance to subterranean and dry wood termites attack," International Biodeterioration and Biodegradation 70, 79-81. DOI: 10.1016/j.ibiod.2011.06.010

Hadi, Y. S., Rahayu, L. S., and Danu, S. (2013). "Physical and mechanical properties of methyl methacrylate impregnated jabon wood," Journal of the Indian Academy of Wood Science 10(2), 77-80. DOI: 10.1007/s13196-013-0098-3

Hadi, Y. S., Effendi, M., Massijaya, M. Y., Arinana, A., and Pari, G. (2016). "Technical note: Subterranean termite resistance of smoked glued laminated lumber made from fast-growing tree species from Indonesia," Wood Fiber Sciences 48(3), 211-216.

Hadi, Y. S., Massijaya, M. Y., Zaini, L. H., and Pari, R. (2019). "Physical and mechanical properties of methyl methacrylate-impregnated wood from three fastgrowing tropical tree species," Journal of Korean Wood Science and Technology 47(3), 324-335. DOI: 10.5658/Wood.2018.46.2.143.

Hadi, Y. S., Massijaya, M. Y., Abdillah, I. B., Pari, G., and Arsyad, W. O. M. (2020a). "Color change and resistance to subterranean termite attack of mangium (Acacia mangium) and sengon (Falcataria moluccana) smoked wood," Journal of Korean Wood Science and Technology 48(1), 1-11. DOI: 10.5658/WOOD.2020.48.1.1

Hadi, Y. S., Massijaya, M. Y., Nandika, D., Arsyad, W. O. M., Abdillah, I. B., Setiono, L., and Amin, Y. (2020b). "Color change and termite resistance of fast-growing tropical woods treated with kesambi (Schleichera oleosa) smoke," Journal of Wood Science 66(1), 61. DOI: 10.1186/s10086-020-01906-y

Hendrik, J., Hadi, Y. S., Massijaya, M. Y., and Santoso, A. (2016). "Properties of 
laminated panels made from fast-growing species glued with mangium tannin adhesive," BioResources 11(3), 5949-5960. DOI: 10.15376/biores. 11.3.5949-5960

Herliyana, E. N., Maryam, L. F., and Hadi, Y. S. (2011). "Schizophyllum commune Fr. sebagai jamur uji ketahanan kayu Standar Nasional Indonesia pada empat jenis kayu rakyat: Sengon (P. falcataria), karet (H. brasiliensis), tusam (P. merkusii), mangium (A. mangium) [Schizophyllum commune Fr. as Indonesian National Standard wood resistance test fungi on four kinds of community wood: Sengon, rubber, tusam, and mangium]," J. Silvikult. Trop. 2(3), 176-180.

Irawanto, R. (2013). "Distribution study of Corypha utan Lamk. from Herbarium Bogorienses specimens and the conservation areas in East Java," in: Proceedings of the 4th International Conference on Global Resource Conservation \& 10th Indonesian Society for Plant Taxonomy Congress, Brawijaya University, Malang, Indonesia, 7-8 February 2013, pp. 135-144.

JAS 234-2003 (2003). “Glued laminated timber," Ministry of Agriculture, Forestry, and Fisheries, Tokyo, Japan.

Komariah, R. N., Hadi Y. S., Massijaya, M. Y., and Suryana, J. (2015). "Physicalmechanical properties of glued laminated timber made from tropical small-diameter logs grown in Indonesia," Journal of Korean Wood Science and Technology 43(2), 156-167. DOI: 10.5658/WOOD.2015.43.2.156

Kretschmann, D. E., and Green, D. W. (1996). "Modelling moisture content-mechanical property relationships for clear southern pine," Wood and Fiber Science 28(3), 320327.

Lestari, A. S. R. D., Hadi Y. S., Hermawan, D., and Santoso, A. (2018). "Physical and mechanical properties of glued laminated lumber of pine (Pinus merkusii) and jabon (Anthocephalus cadamba)," Journal of Korean Wood Science and Technology 46(2), 143-148. DOI: 10.5658/WOOD.2018.46.2.143

Massijaya, M. Y., Hadi, Y. S., Hermawan, D., and Hadjib, N. (2011). "Project completion report: Activity 2.1.4 evaluation of the appropriate properties of products manufactured from small diameter logs in Indonesia," Faculty of Forestry, Bogor Agricultural University, Bogor, Indonesia.

Massijaya, M. Y. (2014). Final Report National Medium-term Development Plan (RPJMN) for Forestry Sector 2015-2019, Prepared for Planning Bureau Ministry of Forestry Republic of Indonesia. Sponsored by Deutsche Gesselschaft fur Internationale Zusammenarbeit (GIZ) GmbH, Germany.

Ministry of Environment and Forestry (2020). Statistic of Forestry Production in 2019 Ministry of Environment and Forestry, Jakarta, Indonesia. https://www.menlhk.go.id/site/single_post/3714/statistik-klhk-2019

Moody, R. C., Hernandez, R., and Liu, J. Y. (1999). "Chapter 11: Glued structural timbers," in: Wood Handbook: Wood as an Engineering Material, U.S. Department of Agriculture Forest Products Laboratory, Madison, WI, USA, pp. 1-24.

Nandika, D., Yudi, R., and Farah, D. (2015). Rayap: Biologi dan Pengendaliannya [Termite: Biology and Its Control], Muhammadiyah University Press, Surakarta, Indonesia.

Nandika, D. (2018). Resistance of Gewang (Corypha Utan Lamk.) Wood to Powder-Post Beetle and Stain Fungus, Unpublished Project Report, Faculty of Forestry, Institut Pertanian Bogor University, Bogor, Indonesia.

Nandika, D., Darmawan, W., Karlinasari, L., Hadi, Y. S., Abdillah, I. B., and Hiziroglu, S. (2020). "Evaluation of color change and biodeterioration resistance of gewang 
(Corypha utan Lamk.) wood," Applied Sciences 10(21), Article number 7501. DOI: 10.3390/app10217501

Prabuningrum, D. S., Massijaya M. Y., Hadi Y. S., and Abdillah I. B. (2020). "Physicalmechanical properties of laminated board made from oil palm trunk (Elaeis guineensis Jacq.) waste with various lamina compositions and densifications," $J$. Korean Wood Sci. Technol. 48(2), 196-205, DOI: 10.5658/WOOD.2020.48.2.196

Pramunendar, R. A., and Supriyanto, C. (2014). "Klasifikasi kualitas kayu kelapa menggunakan gray-level-co-occurrence martix berbasis backpropagation dan algoritma genetika [Quality classification of coconut wood using gray-level cooccurrence matrix based on backpropagation and genetic algorithms]," Semantik 4(1), 250-253.

Prasetiyo, K. W., Subyakto, S., and Naiola, B. P. (2008). "Sifat fisik dan mekanik batang gewang (Corypha utan Lamk.) dari Nusa Tenggara Timur [Physical-mechanical properties of gewang (Corypha utan Lamk.) trunk from East Nusa Tenggara]," Journal of Tropical Forest Science Tech. 6(1), 1-6.

Santoso, A., Hadi, Y. S., Pizzi, A., and Lagel, M. (2016). "Characterization of merbau wood extract used as an adhesive in glued laminated lumber," Forest Products Journal 66 (5-6), 313-318. DOI: 10.13073/FPJ-D-15-00080

SNI 7207-2014 (2014). "Wood and wood products resistance test to wood-destroying organism," Indonesian National Standard Bureau, Jakarta, Indonesia.

Subyakto, S., Prasetiyo, K. W., Subiyanto, B., and Naiola, B. P. (2005). "Potential biomass of Gewang (Corypha utan Lamk.) for biocomposites," in: Proceedings of the 6th International Wood Science Symposium: Towards Ecology and Economy Harmonization of Tropical Forest Resources, Bali, Indonesia, 29-31 August 2005, pp. 58.

Article submitted: September 14, 2021; Peer review completed: October 17, 2021; Revised version received: October 24, 2021; Accepted: October 25, 2021; Published: October 28, 2021.

DOI: 10.15376/biores.16.4.8320-8337 